\title{
Evaluating the fitness of human lysozyme transgenic dairy goats: growth and reproductive traits
}

\author{
Kathryn A. Jackson · Jolene M. Berg • \\ James D. Murray $\cdot$ Elizabeth A. Maga
}

Received: 28 September 2009/Accepted: 19 January 2010/Published online: 5 February 2010

(C) The Author(s) 2010. This article is published with open access at Springerlink.com

\begin{abstract}
While there are many reports in the literature describing the attributes of specific applications of transgenic animals for agriculture, there are relatively few studies focusing on the fitness of the transgenic animals themselves. This work was designed to gather information on genetically modified food animals to determine if the presence of a transgene can impact general animal production traits. More specifically, we used a line of transgenic dairy goats expressing human lysozyme in their mammary gland to evaluate the reproductive fitness and growth and development of these animals compared to their non-transgenic counterparts and the impact of consuming a transgenic food product, lysozyme-containing milk. In males, none of the parameters of semen quality, including semen volume and concentration, total sperm per ejaculate, sperm morphology, viability and motility, were significantly different between transgenic bucks and non-transgenic full-sib controls. Likewise, transgenic females of this line did not significantly differ in the
\end{abstract}

K. A. Jackson · J. M. Berg · J. D. Murray ·

E. A. Maga $(\bowtie)$

Department of Animal Science, University of California, Davis, One Shields Avenue, Davis, CA 95616, USA

e-mail: eamaga@ucdavis.edu

J. D. Murray

Department of Population Health and Reproduction, University of California, Davis, One Shields Ave, Davis, CA 95616, USA reproductive traits of gestation length and litter size compared to their non-transgenic counterparts. To evaluate growth, transgenic and non-transgenic kid goats received colostrum and milk from either transgenic or non-transgenic does from birth until weaning. Neither the presence of the transgene nor the consumption of milk from transgenic animals significantly affected birth weight, weaning weight, overall gain and post-wean gain. These results indicate that the analyzed reproductive and growth traits were not regularly or substantially impacted by the presence or expression of the transgene. The evaluation of these general parameters is an important aspect of defining the safety of applying transgenic technology to animal agriculture.

Keywords Reproduction - Growth ·

Transgenic · Goats · Lysozyme - Welfare

\section{Introduction}

The health and welfare of animals raised for production purposes is of central importance to the public and producers. For successful applications of genetic engineering (GE) to be included in animal production systems, the health and welfare of these animals must be considered. This would also help to improve the perception of the use of transgenic animals in agriculture as well as public perception of biotechnology in general. Currently, no transgenic animal 
products are approved for consumption. The adoption of transgenesis as an effective tool for animal improvement will not be accepted for commercial use until the questions of the health and welfare of transformed animals are addressed.

The first attempts at GE in animals resulted in some physiological problems in the transgenic animals, attributed to inappropriate control of transgene expression resulting in over expression or expression in undesirable tissues (Pursel et al. 1990). Coupling the gene construct to a promoter with appropriate tissue specificity and expression patterns decreased negative welfare impacts due to transgenic expression (Pursel et al. 2004). However, transgenes introduced by microinjection are randomly integrated into the genomic DNA and disruption of endogenous genes can potentially lead to deleterious results. Studies which evaluate general animal production parameters are therefore helpful in assessing the overall health of a transgenic line.

Animal welfare however is a concept that involves both physical and subjective evaluations of transgenic lines (Dennis 2002; Buehr et al. 2003; Duncan 2005; Wells et al. 2006; Mertens and Rulicke 2007). Van Reenen (2009) has suggested that observations regarding the welfare of a transgenic line should be made at times of transgene expression as well as at different stages of life including gestation and birth, birth to puberty and a period representative of adult life, such as reproductive performance. Therefore, to evaluate the general physical aspects of animal health and welfare, standard measures of reproductive fitness such as semen quality in males and such indices as number of live young born, number of dead born, gestation length, and days to first heat cycle can be used as indicators of reproductive health in females. Another key indicator of health in living organisms is the ability to grow from birth to adulthood in a manner similar to other young of the species. A multitude of factors can affect the growth of an animal such as quality and quantity of feed, management, housing, disease, and temperature. In terms of transgenic animals, the introduction of a foreign gene may also affect the animal depending on the site of transgene integration into the genome and potential interactions of the transgene product in the animal.

Specific studies focusing on the health and welfare of the GE livestock are lacking in the literature. Here, we begin to quantify the impact of transgene presence and expression on general parameters of animal health in our human lysozyme (hLZ) line of transgenic dairy goats. The hLZ line was generated by pronuclear microinjection with a transgene consisting of the hLZ cDNA linked to a bovine $\alpha_{\mathrm{s} 1}$-casein promoter to direct expression of hLZ to the mammary gland (Maga et al. 2003). The transgene is transmitted in a Mendelian fashion (Maga et al. 2006a) and we have maintained the line as hemizygous, currently through the fifth generation. The transgene is expressed in milk at levels of $270 \mu \mathrm{g} / \mathrm{ml}$ without disrupting gross milk composition or milk production parameters (Maga et al. 2006a). The impact of transgene expression has been well-characterized as milk containing the antimicrobial hLZ protein was capable of slowing the growth of mastitis- and cold spoilage-causing bacteria in vitro and increasing shelf-life (Maga et al. 2006b), modulating the levels of coliforms and $E$. coli in the intestine of kid goats and young pigs upon consumption of the milk (Maga et al. 2006c) resulting in a healthier intestinal morphology, resistance to infection by E. coli (Brundige et al. 2008) and a serum metabolite profile of indicative of improved gut health (Brundige et al. 2009).

All results described for this line of transgenic animals to date have been congruent with predictions based on the action of lysozyme expression in the mammary gland. In terms of the impact of the presence of the transgene on the transgenic animal itself, questions as to if the basic functions of these animals are in any way compromised due to the presence and expression of the hLZ transgene have yet to be addressed. This paper examines the growth and reproductive fitness of male and female hLZ transgenic goats and their full-sib controls with the intent of determining if these key production parameters are affected by the genomic integration of the hLZ transgene. Additionally, the health of animals consuming milk with increased levels of lysozyme was assessed to determine the impact of consumption of a transgenic product, specifically milk.

\section{Materials and methods}

Growth trials

Growth trials were conducted over the three-year period between 2006 and 2008. Does were bred in the 
fall to produce kids between late February and early June. Animals enrolled in the study consisted of all offspring from matings between either transgenic males and non-transgenic control females or transgenic females and non-transgenic control males. All non-transgenic animals used for breeding were of the same background as the transgenic line (Alpine and Toggenburg in origin). At birth, both male and female kids were randomly placed into one of two feeding groups with one group receiving colostrum and milk from hLZ transgenic does, and the other receiving colostrum and milk from non-transgenic control does. Transgenic status of each kid was determined by taking ear and umbilical tissue samples at birth and performing transgene-specific PCR (Maga et al. 2003) to determine by day 2 of the trial whether or not the animal carried the transgene. Thus, for each type of milk, there were both transgenic and non-transgenic animals consuming it in order to determine transgene impact, milk impact and any interactions between these variables. In the final year of the study animals were non-randomly assigned to groups to ensure an equal distribution of male and female animals in each of the four groups. Animals were removed from the study if euthanasia was required due to injury or illness. Table 1 shows the number of animals that completed the study from birth to weaning.

In all years of the study, kids were removed from does at birth and each was hand-fed 240-300 ml heat-treated $\left(57^{\circ} \mathrm{C}\right.$ for $60 \mathrm{~min}$ then frozen until needed) colostrum from individual does from their designated feeding group (hLZ or control milk) within $12 \mathrm{~h}$ after birth. The kids were then bottlefed $240-350 \mathrm{ml}$ of pasteurized hLZ or control milk three times daily to approximately 4 days of age when free-choice cooler-feeding was implemented. Standard Thermos ${ }^{\circledR}$ coolers were converted to kid

Table 1 Distribution of animals completing the feeding trial (birth to weaning)

\begin{tabular}{lllll}
\hline & $C^{\mathrm{a}} C^{\mathrm{b}}$ & $C T$ & $T C$ & $T T$ \\
\hline Females & 6 & 8 & 5 & 4 \\
Males & 9 & 8 & 5 & 8 \\
\hline
\end{tabular}

${ }^{a}$ First letter of column heading designates animal type ( $C=$ Control, $T=$ Transgenic)

b Second letter of column indicates type of milk fed ( $C=$ Control, $T=$ Transgenic) feeders by drilling holes in the front of the cooler and fitting rubber nipples in the holes. Coolers were cleaned and ice packs were changed once per day to keep the milk cool and avoid spoilage. The appropriate pasteurized milk was added to each cooler at least twice a day so that each kid received approximately $0.951 \mathrm{milk} / \mathrm{kid} /$ day when younger and up to $2.81 \mathrm{milk} / \mathrm{kid} / \mathrm{day}$ as they grew older. This feeding strategy is standard procedure at our dairy goat facility. Milk for feeding was collected from individual hLZ transgenic ( $n=8$ year $1, n=11$ year 2 , $n=11$ year 3 ) and non-transgenic control does ( $n=54$ in all years) by machine twice daily and pooled into respective containers. Each pool of milk was batch pasteurized to $74^{\circ} \mathrm{C}$ prior to feeding to kids to reduce transmission of caprine arthritis encephalitis virus (CAEV) and other diseases (Greenwood 1993; Peterhans et al. 2004). Pools of milk were typically fed within 3 days or less after pasteurization, and milk older than 7 days was discarded.

Prior to weaning, kids were housed at an indoor animal facility in large cardboard refrigerator boxes until approximately 2-weeks of age, at which time they were moved to group pens with wood shavings and straw for bedding. At 6 weeks of age, they were offered alfalfa hay and pellets, and 4 weeks later beef trace mineral salts. At 110 days of age the animals were weaned. At this time they were moved to outdoor pens, and separated into same-sex groups that were housed adjacent to each other. All animals were housed and cared for according to AAALAC guidelines.

\section{Reproduction-males}

To reduce genetic variation between control and transgenic goats, all full sib males resulting from the breeding of a hLZ transgenic animal and a nontransgenic control animal were used. Non-transgenic control animals used for breeding were Toggenburg, Alpine or crosses of these breeds (the background of the transgenic line). Over three breeding seasons, from 2006 to 2008, a total of 12 control bucks and 12 transgenic bucks were evaluated. Each buck had the semen from his first breeding season evaluated. In addition, in the third year of the study, two hLZ transgenic bucks from the previous year (1 year 167 days old) were included to compare semen parameters from their first year to their second year 
as the bucks matured. First year bucks in the study were between 205 and 282 days of age and between 18 and $30 \mathrm{~kg}$ at the time of the semen collection. Bucks were housed with does occupying adjoining pens to encourage reproductive behavior. Bucks were fed alfalfa hay and pellets daily with unlimited access to fresh water.

Semen collection began at the end of September and continued through early December. All bucks were collected twice, at least 3 days apart, to remove sperm accumulation in the week prior to analysis. Animals were then collected two more times at least 3 days apart for analysis. Collection was accomplished with an artificial vagina (AV) and a doe in heat. Temperature of the water in the AV was maintained at approximately $38-40^{\circ} \mathrm{C}$. A graduated collecting tube attached to the disposable sleeve inside the AV was used to evaluate volume of semen collected. Semen parameters analyzed included volume, concentration, total sperm per ejaculate, morphology, viability and motility (total motility and total progressive motility).

Immediately after collection and determination of volume of ejaculate, semen samples were transferred to the laboratory. In 2006, analysis of the semen was done in a room heated to $41^{\circ} \mathrm{C}$, and in 2007 , the semen was kept in an incubator at $41^{\circ} \mathrm{C}$. Gross motility and color of semen were recorded at this time, but not reported here. A portion of the semen was extended 1:999 with water and sperm concentration (billions sperm $/ \mathrm{ml}$ ejaculate) was determined using a hemocytometer under a microscope at $400 \times$. Two counts were made for each individual and averaged. If the counts differed by $30 \%$ or more, the concentration was reanalyzed using another aliquot of the same sample.

For the remainder of the analyses, the remaining semen was extended 10:990 with buffer consisting of $68 \mathrm{mM}$ sodium citrate, $25 \mathrm{mM}$ sodium bicarbonate, $5.4 \mathrm{mM}$ potassium chloride, $16.7 \mathrm{mM}$ glucose, $17.4 \mathrm{mM}$ sulfanilamide, $10 \%$ fresh chicken egg yolk (fresh eggs defined as eggs laid within $24 \mathrm{~h}$ ), 5,000 IU penicillin and $0.8 \mathrm{mM}$ streptomycin. Viability was measured using a sperm viability stain kit (Fertility Solutions Inc., Cleveland, $\mathrm{OH}$ ). After staining of sperm with Nigrosin and Eosin-Y, counts of live sperm per 100 were conducted under a microscope using a $100 \times$ objective and a $10 \times$ eyepiece. Percent normal morphology was determined with a morphology stain
(Lane Manufacturing Inc., Denver, CO). Number of normal sperm out of 100 was determined under a microscope at $1,000 \times$.

Preliminary trials in 2006 to evaluate motility of sperm were carried out, with data for analysis collected in 2007 and 2008 only. Total progressive and forward motility were determined using the CASA (Computer-Aided Sperm Analysis) system. Prior to assaying sperm motility, samples were diluted to between $25 \times 10^{6}$ and $50 \times 10^{6}$ cells per milliliter to accommodate the parameters of the CASA system.

\section{Reproduction—females}

Information on the reproductive fitness of does was determined by the number of live, dead, and total kids born as well as gestation length. Does were matched for breed, age and parity for the analysis with nontransgenic control does. Dead kids were classified as kids who died within 3 days of birth. Birthing records from 2001 to 2008 were analyzed to determine the kidding history of does. These records followed the reproductive history of 15 control and 9 transgenic does that were related to the founder to, in some cases, the 6th parity. The number of observations among all the does over the 8 years was 82 . The same population of bucks was used for the mating of both transgenic and control does. All animals used in the study were cared for under AAALAC-approved conditions.

\section{Statistical analysis}

Animal weights in 2006 and 2007 were recorded at birth, as well as twice a week to weaning, and at 8,12 and 16 weeks post-weaning. In 2008 animals were weighed at birth and at weeks 1, 3, 8, 10, 11 and 13 . No post-wean weights were recorded in 2008. Data for weaning weights for statistical analysis was obtained from weights at 14 weeks for 2006 and 2007, and in 2008 at 11 and 13 weeks. Only animals that completed the trial from birth to weaning were included in the statistical analysis. All values are reported as the mean $\pm \mathrm{SD}$.

A Proc Mixed Ratio ANCOVA analysis using SAS 9.1 (Cary, NC) was used to detect differences between transgenic and control animals. For the growth data, differences due to transgene, milk, birth 
weight and year effects were determined. Since the rate of growth for males is higher than that of females (Lawrence and Fowler 1997), the data for each sex were separated for analysis. Litter size and birth weight are inversely related in the dairy goat (Salah et al. 1989). Generally animals which demonstrate a lighter than average birth weight will eventually catch up in size to their contemporaries (Lawrence and Fowler 1997). However, to accurately assess growth in a study where litter size ranged from 1 to 4 , both litter size and birth weight were analyzed as classes of covariables in an ANCOVA (data not shown). Birth weight had a smaller mean square error and was therefore used instead of litter size as a class covariate in the final model (birth weight MSE $=6.807$, litter size MSE $=8.850$ ). An ANCOVA was run with gain analyzed as a function of type of animal, milk consumed, birth weight and year of trial. REGWQ was used as the test to determine which group means were different from each other.

For reproduction data, males were grouped by the class (type/year/breed) to which they belonged. Age and weight were additional covariates that were tested in the analysis. Due to the continuous nature of the age (by days) and weight covariables, the Proc Mixed analysis was necessary. For gestation length and number of kids born type/breed identifiers were used, and parity and age were additional covariates. A chi-squared test was used to determine differences in the number of kids born dead. For both data sets, all tests were performed at the $95 \%$ confidence level and assumptions of normality of residuals and normal distribution were tested using Levene's test of homogeneity and Shapiro-Wilk, respectively. No abnormalities were detected.

\section{Results}

Growth

Over the 3 years of the trial (2006-2008), no significant differences were detected in the mean birth weights between transgenic and non-transgenic control females $(P=0.71)$ or males $(P=0.51$; Table 2). In addition, there were no significant differences in mean birth weights among the 3 years of the study in both females and males $(P=0.44$ and $P=0.83$, respectively). Results of the growth
Table 2 Mean birth weights $(\mathrm{kg})$ of hLZ transgenic and nontransgenic control animals

\begin{tabular}{lll}
\hline & Control $^{\mathrm{a}}$ & Transgenic $^{\mathrm{a}}$ \\
\hline Females & $3.68 \pm 0.59$ & $3.65 \pm 0.65$ \\
& $(n=14)$ & $(n=9)$ \\
Males & $3.76 \pm 0.83$ & $3.98 \pm 0.41$ \\
& $(n=17)$ & $(n=12)$ \\
\hline
\end{tabular}

$\overline{{ }^{a}}$ No significant differences were detected between control and transgenic animals $(P>0.05)$

analysis from birth to post-weaning are presented in Table 3. There were no significant differences in overall gain among all groups of females $(P=0.17)$ or males $(P=0.63)$ as well as no differences due to year $(P=0.06$ females, $P=0.57$ males $)$. Weaning weights were not significantly different for females $(P=0.11)$ or males $(P=0.67)$ of all groups. There was no effect of year on weaning weight in males $(P=0.67)$ but there was for females $(P=0.05)$. Females of all groups did not gain weight at significantly different rates $(P=0.09)$ and the slope of gain for males of all groups was also not significantly different $(P=0.42)$. There was a significant differences in slope by year for both females and males $(P=0.008$ and $P=0.0083$, respectively). The post-wean gain in weight was not significantly different among any group of males $(P=0.49)$ nor was there a year effect $(P=0.60)$. Post-wean gain in females was not significantly different by year $(P=0.52)$ or by group $(P=0.19)$.

To evaluate the impact of consuming hLZ milk, an ANCOVA was run including birth weight, year and milk type as co-variables. Neither birth weight, year, nor type of milk consumed affected the overall growth (birth to wean) of transgenic females $(P=0.80,0.96$ and 0.90 , respectively), non-transgenic females $(P=0.88,0.56$ and 0.55 , respectively), transgenic males $(P=0.53,0.08$ and 0.19 respectively) and non-transgenic males $(P=0.30$, 0.71 and 0.68 , respectively). To analyze the impact of the transgene, an ANCOVA was performed using birth weight, year and transgenic status as covariables. Overall growth (birth to wean) of animals consuming non-transgenic milk was not impacted by the presence of the transgene, birth weight or year of the trial $(P=0.50,0.70$ and 0.66 , respectively for females and $P=0.65,0.62$ and 0.67 , respectively for males). Similar results were found for the 
Table 3 Growth parameters of hLZ transgenic and non-transgenic control animals consuming milk from hLZ transgenic or nontransgenic control does

\begin{tabular}{|c|c|c|c|c|}
\hline & $\mathrm{CC}^{\mathrm{a}}$ & $\mathrm{CT}^{\mathrm{b}}$ & $\mathrm{TC}^{\mathrm{c}}$ & $\mathrm{TT}^{\mathrm{d}}$ \\
\hline \multicolumn{5}{|c|}{ Overall gain birth to wean $(\mathrm{kg})$} \\
\hline Females & $\begin{array}{l}20.42 \pm 1.01 \\
(n=6)\end{array}$ & $\begin{array}{l}19.15 \pm 3.42 \\
(n=8)\end{array}$ & $\begin{array}{l}19.74 \pm 3.10 \\
(n=5)\end{array}$ & $\begin{array}{l}21.32 \pm 2.39 \\
(n=4)\end{array}$ \\
\hline Males & $\begin{array}{l}23.35 \pm 3.28 \\
(n=9)\end{array}$ & $\begin{array}{l}24.09 \pm 3.13 \\
(n=8)\end{array}$ & $\begin{array}{l}24.85 \pm 2.92 \\
(n=5)\end{array}$ & $\begin{array}{l}22.89 \pm 3.55 \\
(n=7)\end{array}$ \\
\hline \multicolumn{5}{|c|}{ Weaning weight $(\mathrm{kg})$} \\
\hline Females & $\begin{array}{l}24.40 \pm 0.94 \\
(n=6)\end{array}$ & $\begin{array}{l}22.61 \pm 3.75 \\
(n=8)\end{array}$ & $\begin{array}{l}23.27 \pm 2.73 \\
(n=5)\end{array}$ & $\begin{array}{l}25.11 \pm 2.42 \\
(n=4)\end{array}$ \\
\hline Males & $\begin{array}{l}27.22 \pm 3.84 \\
(n=9)\end{array}$ & $\begin{array}{l}27.73 \pm 3.40 \\
(n=8)\end{array}$ & $\begin{array}{l}28.91 \pm 3.19 \\
(n=5)\end{array}$ & $\begin{array}{l}26.82 \pm 3.32 \\
(n=7)\end{array}$ \\
\hline \multicolumn{5}{|c|}{ Slope of gain (kg/day) } \\
\hline Females & $\begin{array}{l}0.22 \pm 0.03 \\
(n=6)\end{array}$ & $\begin{array}{l}0.18 \pm 0.03 \\
(n=8)\end{array}$ & $\begin{array}{l}0.23 \pm 0.03 \\
(n=5)\end{array}$ & $\begin{array}{l}0.20 \pm 0.02 \\
(n=4)\end{array}$ \\
\hline Males & $\begin{array}{l}0.22 \pm 0.03 \\
(n=9)\end{array}$ & $\begin{array}{l}0.23 \pm 0.02 \\
(n=8)\end{array}$ & $\begin{array}{l}0.24 \pm 0.04 \\
(n=5)\end{array}$ & $\begin{array}{l}0.25 \pm 0.05 \\
(n=7)\end{array}$ \\
\hline \multicolumn{5}{|c|}{ Post-wean gain $(\mathrm{kg})$} \\
\hline Females & $\mathrm{NA}^{\mathrm{e}}$ & $\begin{array}{l}16.31 \pm 4.23 \\
(n=8)\end{array}$ & $\mathrm{NA}^{\mathrm{e}}$ & $\begin{array}{l}17.02 \pm 3.68 \\
(n=4)\end{array}$ \\
\hline Males & $\begin{array}{l}17.72 \pm 7.90 \\
(n=7)\end{array}$ & $\begin{array}{l}13.47 \pm 4.34 \\
(n=7)\end{array}$ & $\begin{array}{l}14.35 \pm 5.52 \\
(n=5)\end{array}$ & $\begin{array}{l}20.00 \pm 8.77 \\
(n=3)\end{array}$ \\
\hline
\end{tabular}

${ }^{a}$ Non-transgenic control animals consuming milk from non-transgenic does

b Non-transgenic control animals consuming milk from hLZ transgenic does

c hLZ transgenic animals consuming milk from non-transgenic does

d hLZ transgenic animals consuming milk from hLZ transgenic does

e Not statistically analyzed due to small group size ( $<3$ animals)

Table 4 Semen parameters from hLZ transgenic and non-transgenic control bucks

\begin{tabular}{llllll}
\hline & Volume $(\mathrm{ml})$ & $\begin{array}{l}\text { Concentration (billions } \\
\text { sperm/ml ejaculate })\end{array}$ & $\begin{array}{l}\text { Total sperm } \\
\text { per ejaculate }\end{array}$ & $\begin{array}{l}\text { Morphology } \\
(\% \text { normal })\end{array}$ & $\begin{array}{l}\text { Viability } \\
(\% \text { live })\end{array}$ \\
\hline Control $(n=12)$ & $0.84 \pm 0.28$ & $2.57 \pm 1.69$ & $2.36 \pm 2.02$ & $88.43 \pm 5.34$ & $76.04 \pm 11.48$ \\
Transgenic $(n=12)$ & $1.00 \pm 0.25$ & $3.20 \pm 1.74$ & $3.34 \pm 2.25$ & $88.10 \pm 5.92$ & $82.35 \pm 9.19$ \\
\hline
\end{tabular}

No significant differences were detected between control and transgenic animals $(P>0.05)$

consumption of milk from hLZ transgenic animals. There were no significant differences in transgene status, birth weight or year for both females $(0.17$, 0.92 and 0.12 , respectively) and males $(P=0.73$, 0.94 and 0.67 , respectively).

\section{Reproduction}

Measures of reproductive fitness in the bucks throughout the 3 years of the study are reported in Tables 4 ,
5,6. No significant differences between transgenic and non-transgenic control males were detected in semen volume $(P=0.61)$, concentration $(P=0.86)$, total sperm per ejaculate $(P=0.86)$, morphology $(P=0.15)$ or viability $(P=0.55)$ (Table 4$)$. No significant differences in semen motility were demonstrated between the two groups of animals in terms of both total motility $(P=0.50)$ and total progressive motility $(P=0.41$; Table 5$)$. Table 6 compares the semen parameters in two transgenic bucks that were collected 
Table 5 Semen motility of control and hLZ transgenic bucks

\begin{tabular}{lll}
\hline & $\begin{array}{l}\text { Total } \\
\text { motility }(\%)\end{array}$ & $\begin{array}{l}\text { Total progressive } \\
\text { motility }(\%)\end{array}$ \\
\hline Control $(n=9)$ & $64.28 \pm 15.26$ & $39.65 \pm 14.14$ \\
Transgenic $(n=5)$ & $60.00 \pm 17.93$ & $35.07 \pm 14.04$ \\
\hline
\end{tabular}

No significant differences were detected between control and transgenic animals $(P>0.05)$

in their first and second breeding seasons to determine whether normal reproductive status was maintained beyond the first breeding season. No gross deviations between the years for either buck were evident.

In Table 7, a summary of the reproductive status of does in the hLZ line is represented by their kidding history. There were no significant differences in the parameters of days of gestation $(P=0.20)$, live kids born $(P=0.39)$ and total kids born $(P=0.22)$ among groups of non-transgenic control does and hLZ transgenic does. There were no significant differences in the number of dead kids born among transgenic and non-transgenic does $\left(\chi^{2}=0.544\right.$, $P>0.05)$.

\section{Discussion}

Studies such as this one that examines basic functions will be useful in determining the impact of GE on animal health. It has been suggested that three aspects of the welfare of a transgenic line should be evaluated including the effects of insertional mutagenesis, transgene expression and, if applicable, effects of in vitro reproduction technologies if somatic cell nuclear transfer techniques were used to generate the transgenic line (Van Reenen 2009). As the hLZ transgenic line was generated by pronuclear microinjection,
Table 7 Kidding history of the hLZ transgenic line

\begin{tabular}{llll}
\hline & $\begin{array}{l}\text { Gestation } \\
\text { (days) }\end{array}$ & Live born & Total born \\
\hline $\begin{array}{c}\text { Control } \\
(n=9)\end{array}$ & $152.20 \pm 4.15$ & $2.38 \pm 0.92$ & $2.56 \pm 0.75$ \\
$\begin{array}{c}\text { Transgenic } \\
(n=15)\end{array}$ & $151.22 \pm 3.91$ & $1.98 \pm 0.78$ & $2.21 \pm 0.71$ \\
\hline
\end{tabular}

No significant differences were detected between control and transgenic animals $(P>0.05)$

insertional mutagenesis and transgene expression would be of concern. Copy number as determined by real-time PCR along with transgene insertion site mapping results via an inverse PCR strategy have verified that two copies of the $\alpha_{\mathrm{s} 1} \mathrm{HLZ}$ transgene are integrated into the genome in a head-to-tail fashion. Analysis of the sequence at the $3^{\prime}$ insertion site by BLAST indicates that the transgene is not integrated into any currently known genes (data not shown). As the goat genome has yet to be sequenced, the majority of the matches were with bovine genomic repetitive DNA analogous to the L1-art repeat family. Furthermore, preliminary analysis of mRNA from a tissue panel (ear, skin, muscle, fat, mammary gland, liver, kidney, spleen, salivary gland, heart, lung, uterus, ovary and intestine) from three individual lactating transgenic females by reverse transcriptase PCR demonstrated that expression of the transgene was restricted to the lactating mammary gland (data not shown). Therefore, we would not anticipate any major impact resulting from insertional mutagenesis or offtissue expression of the transgene on the general welfare of this line of transgenic animals.

To begin to evaluate aspects of animal welfare of the hLZ transgenic line, relevant measures of welfare would comprise assessing general measures such as
Table 6 Reproduction parameters of yearling and mature transgenic males

\begin{tabular}{clllll}
\hline & $\begin{array}{l}\text { Volume } \\
(\mathrm{ml})\end{array}$ & $\begin{array}{l}\text { Viability } \\
(\%)\end{array}$ & $\begin{array}{l}\text { Morphology } \\
(\% \text { normal })\end{array}$ & $\begin{array}{l}\text { Concentration } \\
(\text { sperm } / \mathrm{ml} \\
\text { ejaculate })\end{array}$ & $\begin{array}{l}\text { Total sperm/ } \\
\text { ejaculate } \\
\text { (billions })\end{array}$ \\
\hline $\begin{array}{c}\text { Buck 7028 } \\
\text { Yearling }\end{array}$ & 0.75 & 80 & 88 & 3.03 & 2.44 \\
Mature & 1.50 & 76 & 90 & 4.65 & 6.97 \\
Buck 7032 & & & & & 5.11 \\
Yearling & 1.07 & 84 & 89 & 4.75 & 6.10 \\
Mature & 1.00 & 90 & 91 & 6.10 & \\
\hline
\end{tabular}


health (clinical signs of disease), production traits, reproduction and growth (Broom 1993). Here, several parameters associated with reproduction and growth of hLZ transgenic and non-transgenic dairy goats were evaluated to assess the fitness of this line of transgenic dairy goats when compared with their control siblings. None of the reproductive traits, growth periods, or rate of growth were affected by presence of the transgene, or the consumption of milk from $\mathrm{hLZ}$ transgenic does.

\section{Growth}

In agreement with our data on insertion site, the site of integration of the transgene did not appear to interrupt an endogenous gene for growth in utero, as both groups of animals, transgenic and nontransgenic controls, demonstrated no significant differences in birth weights. The males did have, on average, higher birth weights than the females for both groups, as is common in most mammals (Lawrence and Fowler 1997). In addition, there were no differences in birth weights detected during the 3 years of the trial, indicating that any environmental differences between the years of the study had no impact on the prenatal growth of the kids.

Overall gain from birth to weaning was not significantly different for either the males or the females among groups. There were also no differences detected by year of the trial or birth weight for overall gain. These results indicate that all groups of animals, whether transgenic or not, and whether drinking control or transgenic milk, gained mass in a similar manner from their birth to weaning. As with birth weights, the gain in these animals realized between birth and weaning was higher on average for males than for females.

Weaning weights in females although not significantly different among groups, demonstrated a difference among years of the study. Weaning weights were lowest in 2006, but not significantly different from weaning weights in 2008. The difference in weaning weights of does in the feeding trial in years 2006 and 2007 could have been due to such factors as management changes which occurred between these 2 years and the genetics of the nontransgenic control animals used for breeding. Since no differences were detected in the weaning weights among the groups, the co-variables that contributed to the differences seen among mean weaning weights between 2006 and 2007 do not indicate differences due to animal or milk type. Since a variety of nontransgenic control bucks were used to generate the new crop of kids each year, genetics of the sires may have contributed to the differences in mean weaning weights demonstrated between the first 2 years of the trial. There were no significant differences in weaning weights detected among the groups of males, and year effects did not significantly affect the weaning weight in males.

The rate at which the groups of both males and females gained weight was not significantly different, except by year of the trial in both males and females. The average rate of gain for the does in the study ranged between 0.18 and $0.23 \mathrm{~kg}$ per day, well within the range of $0.02-0.3 \mathrm{~kg}$ per day reported in the literature for growing female kids (National Research Council 2006). In males, the slope of gain from birth to weaning ranged from an average of $0.22-0.25 \mathrm{~kg}$ per day, compared with $0.02-$ $0.30 \mathrm{~kg}$ per day reported in the literature for male dairy goats of similar age (National Research Council 2006).

The comparisons of non-transgenic animals and transgenic animals drinking either hLZ milk or control milk demonstrated that all groups grew similarly. This line of transgenic dairy goats appears to have a normal pattern of growth during both the prenatal and postnatal period when compared with their full-sibs which do not carry the transgene. The consumption of milk from hLZ transgenic dairy goats does not appear to negatively impact growth in either males or females in this line of transgenic dairy goats, nor their non-transgenic siblings.

Details of illness, disease outbreaks and injuries, were maintained during the duration of the trial. Scours outbreaks occurred twice in 2007 , once in a pen of control kids, and once in a pen of transgenic kids, resulting in diarrhea, dehydration and inappetance in the affected animals. Treatment (Albon) was administered as recommended by the clinical veterinarian, and the animals returned to a healthy status. Over the 3 years, a total of six animals (three transgenic and three non-transgenic controls) did not complete the trial and either died or were euthanized. The three transgenic kids (all consuming control milk) were all euthanized due to physical ailments/defects. One kid suffered a broken leg, one 
had a congenital central nervous system defect and one was a hermaphrodite. All of these conditions are noted to occur in the general goat population and our herd records gave no indication that transgenic animals were more likely to suffer these conditions than their non-transgenic herdmates. In contrast, the three non-transgenic kids all died due to bacterial infections with the causes of death being either enteric coccidiosis or enterotoxemia caused by Clostridium perfringens. It is interesting to note that the three animals which died due to bacterial-related issues of the gastrointestinal tract were all consuming non-transgenic milk. This may indicate an improved resistance to common gastrointestinal infections caused by microorganisms in animals which consume hLZ milk. Although no formal statistical analysis was applied to the information gathered on death and illness in the trial animals, the heath of the transgenic animals did not appear to be any different than their control siblings, or different from goats in other dairy goat populations that are subject to the same types of diseases, defects and injuries.

Overall, neither the consumption of hLZ transgenic milk nor the presence of the hLZ transgene in the genome of the hLZ line of dairy goats caused detrimental effects on birth weight, weaning weight, overall gain or rate of gain. Although some differences were found among groups in the feeding trial over 3 years due to year effects, there is no pattern of consistently altered growth in any group, and in fact the rate of gain for all groups of both sexes is relatively high when compared with the industry average.

\section{Reproduction-males}

Bucks from the hLZ transgenic line were not significantly different from non-transgenic control bucks in their reproductive ability. The values for the semen traits of both the control and transgenic bucks were within the normal range for goats; volume 0.1$1.5 \mathrm{ml}$, concentration $2-6$ billion sperm per $\mathrm{ml}$ ejaculate, viability $82-93 \%$, normal morphology 80-95\% and total motility 54-80\% (Hafez 1980; Hafez and Hafez 2000; Nur et al. 2005). In addition, normal maturation of semen quality with increasing age was demonstrated in two hLZ transgenic bucks which had semen analyzed and compared in both their first and second breeding seasons.
Over the 3 year period, a total of five animals were available but could not successfully be collected. Two transgenic and two non-transgenic controls were never successfully collected due to behavioral problems (unwilling and/or unmanageable behavior) and one non-transgenic control failed to show any signs of breeding behavior. Overall, the presence of the hLZ transgene in the genome of these animals does not appear to interfere with normal semen production. Similar findings have been reported for transgenic cattle and rabbits (Richt et al. 2006; Chrenek et al. 2007).

\section{Reproduction-females}

No significant differences were detected between the hLZ transgenic does and the non-transgenic controls in any of the recorded reproductive parameters. No transgenic doe gave birth to a litter that exceeded three neonates and litter size was not significantly different from the control does. The number of dead born kids to the transgenic line was also not significantly different from control animals. The only sexual aberration identified in this study was the hermaphrodite transgenic female born in 2008. In livestock this condition is most common in cattle, goats and pigs (Bliss et al. 1992) and has been seen in our control goat population as well.

Other parameters of female reproductive fitness, such as a fertilization assay which would demonstrate both the efficiency of the sperm's ability to fertilize the egg, and the quality of the egg itself are more invasive measures that could be taken to examine the reproductive health of this line of transgenic goats, but as we require lactating females for the study of the applications of this line, this type of work was not carried out for this study. However, the production of the same total number of kids born to both the nontransgenic control does and the hLZ transgenic does over 8 years demonstrates the efficiency of reproduction of the hLZ transgenic does.

The evaluation of the health, well-being and behavior of transgenic animals are important aspects of defining the safety of applying transgenic technology to animal agriculture. While it is likely that large numbers of animals may be required to detect a small but biologically significant impact on welfare, deleterious effects could be identified with fewer study subjects (Van Reenen 2009). In this study, we report 
no major differences in the tested parameters of reproductive efficiency or growth of the line. This coupled with our previous characterization of the line suggests that standard reproduction indices and weight development in this line of transgenic goats are not compromised due to the presence and expression of the transgene. Information of this nature can help contribute to the knowledge required to make science-based regulatory decisions regarding the use of transgenic animals in agriculture. The ability to create a line of animals with novel and beneficial products will only be accepted for use by consumers and regulators if the general good health and well-being of the animals has been established.

Acknowledgments We kindly thank Trish Berger for useful discussions, facility manager Jan Carlson for expert animal care and sample collection, and Sophia Najera and Sergio German for animal assistance. This work was funded by USDA CSREES/NRI 2005-55204-15.

Open Access This article is distributed under the terms of the Creative Commons Attribution Noncommercial License which permits any noncommercial use, distribution, and reproduction in any medium, provided the original author(s) and source are credited.

\section{References}

Bliss EL, Oltenacu EA, Ott RS (1992) Reproductive management. In: National Goat Handbook. University of Maryland.

Broom DM (1993) Assessing the welfare of modified or treated animals. Livest Prod Sci 36:39-54

Brundige DR, Maga EA, Klasing KC, Murray JD (2008) Lysozyme transgenic goats' milk influences gastrointestinal morphology in young pigs. J Nutr 138:921-926

Brundige DR, Maga EA, Klasing KC, Murray JD (2009) Consumption of pasteurized human lysozyme transgenic goats' milk alters serum metabolite profile in young pigs. Transgenic Res. doi: 10.1007/s11248-009-9334-4

Buehr M, Hjorth JP, Hansen AK, Sandoe P (2003) Genetically modified laboratory animals-What welfare problems do they face? J Appl Anim Welf Sci 6:319-338

Chrenek P, Trandzik J, Massanyi P, Makarevich A, Lukac N, Peskovicova D, Paleyanda R (2007) Effect of transgeneis on reproductive traits of rabbit males. Ani Reprod Sci 99:127-134

Dennis MB (2002) Welfare issues of genetically modified animals. ILAR J 43:100-109

Duncan JJ (2005) Science-based assessment of animal welfare: farm animals. Rev Sci Tech 24:483-492

Greenwood PL (1993) Rearing systems of dairy goats. Small Rum Res 10:189-199

Hafez ESE (1980) Reproduction in farm animals. Lea \& Febiger, New York
Hafez ESE, Hafez B (2000) Reproduction in farm animals. Wiley-Blackwell, New York

Lawrence TLJ, Fowler VR (1997) Growth of farm animals. CABI Publishing, Wallingford

Maga EA, Sargent RG, Zeng H, Pati S, Zarling DA, Oppenheim SM, Collette NMB, Moyer AL, Conrad-Brink JS, Rowe JD, BonDurant RH, Anderson GB, Murray JD (2003) Increased efficiency of transgenic livestock production. Transgenic Res 12:485-496

Maga EA, Shoemaker CF, Rowe JD, BonDurant RH, Anderson GB, Murray JD (2006a) Production and processing of milk from transgenic goats expressing human lysozyme in the mammary gland. J Dairy Sci 89:518-524

Maga EA, Cullor JS, Smith W, Anderson GB, Murray JD (2006b) Human lysozyme expressed in the mammary gland of transgenic dairy goats can inhibit the growth of bacteria that cause mastitis and the cold spoilage of milk. Foodborne Patho Dis 3:384-392

Maga EA, Walker RL, Anderson GB, Murray JD (2006c) Consumption of milk from transgenic goats expressing human lysozyme in the mammary gland results in the modulation of intestinal microflora. Transgenic Res 15:515-519

Mertens C, Rulicke T (2007) Welfare assessment and phenotype characterization of transgenic mice. ALTEX 24:46-48

National Research Council (2006) Nutrient requirements of small ruminants. The National Academies Press, Washington, DC

Nur Z, Dogan I, Gunay U, Kemal Soylu M (2005) Relationship between sperm membrane integrity and other semen quality characteristics of the semen of Saanen goat bucks. Bull Veterinary Institute Pulawy 49:183-187

Peterhans E, Greenland T, Badiola J, Harkiss G, Bertoni G, Amorena B, Eliaszewicz M, Juste RA, Krabnig R, Lafonte J-P, Lenihan P, Petursson G, Pritchard G, Thorley J, Vitu C, Mornex J-F, Pepin M (2004) Routes of transmission and consequences of small ruminant lentiviruses (SRLVs) infection and eradication schemes. Vet Res 35:257-274

Pursel VG, Hammer RE, Bolt DJ, Palmiter RD, Brinster RL (1990) Integration, expression and germ-line transmission of growth-related genes in pig. J Repro Fert Suppl 41:77-87

Pursel VG, Mitchell AD, Bee G, Elsasser TH, McMurtry JP, Wall RJ, Coleman ME, Scwartz RJ (2004) Growth and tissue accretion rates of swine expressing an insulin-like growth factor I transgene. Ani Biotechnol 15:33-45

Richt JA, Kasinathan P, Hamir AN, Castilla J, Sathiyaseelan T, Vargas F, Sathiyaseelan J, Wu H, Matsushita H, Koster J, Kato S, Ishida I, Soto C, Robl JM, Kuroiwa Y (2006) Production of cattle lacking prion protein. Nat Biotechnol 25:132-138

Salah MS, Bakkar MN, Mogawer HH (1989) Body weight of Aradi goat kids in Saudi Arabia at different ages and affecting factors. J King Saudi University 1:17-24

Van Reenen CG (2009) Assessing the welfare of transgenic farm animals. In: Engelhard M, Hagen K, Boysen M (eds) Genetic engineering in livestock, new applications and interdisciplinary perspectives. Springer, Berlin, pp 119-143

Wells DJ, Playle LC, Enser WEJ, Flecknell PA, Gardiner MA, Holland J, Howard BR, Hubrecht R, Humphreys KR, Jackson IJ, Lane N, Maconochie M, Mason G, Morton DB, Raymond R, Robinson V, Smith JA, Watt N (2006) Assessing the welfare of genetically altered mice. Lab Anim 40:111-114 